\title{
The Effects of Sugars Intake and Frequency of Ingestion on Dental Caries Increment in a Three-year Longitudinal Study
}

\author{
B.A. BURT, S.A. EKLUND, K.J. MORGAN'1, F.E. LARKIN, K.E. GUIRE, L.O. BROWN, and J.A. WEINTRAUB
}

School of Public Health, The University of Michigan, Ann Arbor, Michigan 48109-2029

A three-year longitudinal study was carried out with a group of children, initially aged $11-15$, residing in non-fluoridated rural communities in south-central Michigan. This report analyzes the relation between caries increment and consumption of sugars from all sources to see if accepted relationships have changed with the caries decline in the United States. There were 499 children who provided three or more 24-hour dietary recall interviews, and who received dental examinations at baseline and after three years.

Caries increment averaged 2.91 DMFS over the three years, with $81 \%$ of new lesions on pit-and-fissure surfaces. Consumption of sugars from all sources averaged $156 \mathrm{~g}$ per day for males and $127 \mathrm{~g}$ per day for females, an average of $52 \mathrm{~kg}$ per person per year. Sugars constituted one-quarter of total caloric intake for both boys and girls, and the average number of eating occasions per day was 4.3.

Children who consumed a higher proportion of their total energy intake as sugars had a higher increment of approximal caries, though there was little relation to pit-and-fissure caries. The average number of daily eating occasions was not related to caries increment, nor was the average number of sugary snacks (defined as foods with $15 \%$ or more of sugars) consumed between meals, but the average consumption of between-meal sugars was related to the approximal caries increment. When children were categorized by high caries increment compared with no caries increment, a tendency toward more frequent snacks was seen in the high-caries children.

In an age of generally declining caries, it was concluded that higher average daily consumption of sugars, and higher between-meal consumption of sugars, was still a risk factor for children susceptible to approximal caries. Overall frequency of eating and frequency of ingestion of sugary foods between meals, however, were both poorly related to approximal caries increment. Pit-and-fissure caries could not be related to any aspect of sugars consumption.

\section{J Dent Res 67(11):1422-1429, November, 1988}

\section{Introduction.}

Within the multifactorial context, sugars are a cause of dental caries (Makinen, 1972; Finn and Glass, 1975; Bibby, 1978; Bowen, 1978; Mandel, 1979; Sreebny, 1982a; Newbrun, 1983; Rugg-Gunn and Edgar, 1984). While this relationship had been observed for centuries, Miller (1883) first give it a scientific basis in the late 19th century. The relationship has been confirmed in epidemiological studies through the 1930's (Bunting, 1935; Jay, 1938, 1940; Collins et al., 1942), during World War Il (Toverud, 1956, 1957a, 1957b; Takeuchi, 1961), in studies of unusual dietary patterns in certain population groups (Harris, 1963; Fisher, 1968; Newbrun et al., 1980), and in societies adopting Western dietary patterns over a short period of time (Baume, 1969; Curzon and Curzon, 1970; Pedersen, 1971; Hargreaves, 1972; Moller et al., 1972; Jakobsen, 1979; Schamschula et al., 1980).

While consumption of sugars has long been seen as a cause of caries, the specific nature of the relationship has not been

Received for publication February 19, 1988

Accepted for publication June 23, 1988

${ }^{1}$ Formerly with the Department of Human Nutrition, Foods and Food Systems Management, University of Missouri, Columbia, MO

This study was supported by NIDR Contract DE 22438. well-defined. Frequency of eating is usually considered of greater etiological importance than total sugars consumed (Bowen and Birkhed, 1986), evidence for this view coming from studies with animals (Larson et al., 1962; König et al., 1968; Bowen et al., 1983; Firestone et al., 1984) and with humans (Zita and McDonald, 1959; Weiss and Trithart, 1960; Duany et al., 1972; Hankin et al., 1973; Kohler and Holst, 1973; Clancy et al., 1977; Hargreaves, 1980; U.S. Public Health Service, 1982; Lachappelle-Harvey and Sevigny, 1985). On the other hand, there are also human studies which have failed to show a correlation between caries prevalence and reported frequency of eating (Littleton et al., 1970; Bagramian and Russell, 1973; Bagramian et al., 1974; Richardson et al., 1978). In his comprehensive review, Sreebny (1982a) noted a lack of rigor in some studies of this issue, and concluded that a consistent correlation between frequency of sugars consumption and caries experience in humans had not been demonstrated.

Beliefs on the importance of intake frequency persist, however, most probably because of the profound impact of the Vipeholm study, conducted in a mental institution in Sweden between 1945 and 1952 (Gustafsson et al.,1954). The residents of the institution were placed into nine convenience groups with different amounts, frequencies, and physical forms of sugar intake each day. Subjects in the group which received only $30 \mathrm{~g}$ of sucrose per day, all at meals, averaged 0.27 new carious surfaces per year. These subjects, however, were only slightly better off than those who ingested $330 \mathrm{~g}$ of sucrose per day, with $300 \mathrm{~g}$ of that in solution, and who averaged 0.43 new carious surfaces per year. All of these sugars were taken at mealtimes. At the other extreme, subjects in the group which received 24 sticky toffees per day, each of whom ingested 300 $\mathrm{g}$ of sugar per day but $40 \%$ of which was taken between meals in sticky form, averaged 4.02 new lesions per year. Design flaws suggest that figures from the Vipeholm study should not be taken too literally, but the contrasts in caries increment among the groups are difficult to challenge solely on the basis of study design.

Dental caries has been declining among children in the United States (U.S. Public Health Service, 1981), and so has sucrose as a proportion of total sugars consumption, even though total consumption of sugars has remained steady (Burt, 1985). With caries declining, especially in approximal and smooth surfaces, the impact of present-day consumption of sugars on what is increasingly becoming a pit-and-fissure disease in children has not been determined. To clarify this and related issues, we carried out a three-year longitudinal study with a group of Midwestern teenagers, from 1982 to 1985 . This paper assesses the relation between caries increment and (a) average daily consumption of sugars from all sources; (b) average number of daily eating occasions; (c) average number of between-meal snacks of high-sugar foods; and (d) average daily consumption of sugars between meals.

\section{Materials and methods.}

The study was conducted in the non-fluoridated $(0.2 \mathrm{ppm})$ communities of Coldwater, Quincy, and Union City, Michi- 
gan. Of the families of all schoolchildren initially aged 10-15 who were invited to participate, 747 children ( $55 \%$ of those approached) whose parents or guardians signed informed consent forms were present at the first dental examinations. Caries increment over the three years was determined from the dental examinations in November, 1982 and November, 1985. All dental examinations were conducted by the same two experienced examiners from the National Institute of Dental Research (NIDR), using NIDR's criteria for caries (American Dental Association, 1968). Teeth were dried before examination, transillumination used, and caries diagnosed only when a break in surface enamel was evident. Examiners saw the same children at both examinations, and radiographs were not exposed for ethical reasons. Because these examiners had standardized their diagnoses and had worked together on many studies, their data were pooled, and inter-examiner replicate examinations were not conducted.

Dietary information was collected from a series of 24-hour recall interviews followed by a food frequency questionnaire; most participants were interviewed four times during the study. (The variable number of interviews was arranged to allow for analysis of inter-subject versus intra-subject variability of food intake.) The computer-based Michigan State University (MSU) Nutrient Data Bank (Morgan and Zabik, 1981) was used to convert food items from the 24-hour dietary recall interviews to quantitative estimates of nutrients. As well as quantities of sugars (defined as all naturally-occurring and added mono- and disaccharides, including sucrose, glucose, lactose, maltose, fructose, and other reducing saccharides ingested from all dietary sources) in both natural and processed foods, the bank contained values for many other nutrients in over 4,000 food items. The MSU Nutrient Data Bank allows for assessment of nutrient intake by eating occasion as well as by total daily quantities. It does not, however, include quantities of the different sugars in all foods: Most foods have just "total sugars" listed. It was therefore not possible for the effects of individual sugars on caries in a normal human diet to be analyzed.

An "eating occasion" was defined as ingestion of food or beverage items no more than 20 minutes apart; consumption of food or beverage not defined as part of a meal was considered a snack. Meals and snacks were subjectively defined, meaning that the participant determined whether a cola and a bag of fries at 5 p.m. was dinner or an afternoon snack.

The dietary recall interviews began in November, 1982, a few days before the dental examinations. Interviews were conducted by two dietitians trained in interviewing techniques. Training included duplicate interviews with test subjects until a satisfactory level of standardization was achieved. A third dietitian was employed as a coordinator to collate and check the field interview data prior to computer entry, and to act as a reserve interviewer. The same interviewers stayed with the project for three years. Three sets of duplicate interviews throughout the study ensured that dietary data were being collected in a standardized fashion.

The interview instrument for this study was adapted from that used in the NHANES II national survey of 1976-80; the protocol for its use was based on that for the Bogalusa heart study (Frank et al., 1977). A set of food models in the shapes of bowls, cups, glasses, mounds, spoons, and various slices, plus a set of rectangles to judge size of food portions, provided a visual cue for quantities. These models were the same as those used in the NHANES II survey; each quantity measure was coded for the interview record. The interviewer asked the respondent to recall everything she/he had eaten or drunk the day before, beginning from midnight, and following through the day in a structured, standardized format. As well as all foods and beverages being recorded, time of day when meals or snacks were consumed was also noted. To aid the recall process, the interviewer probed for likely times for snacks (e.g., after school), brand names of foods, food preparation methods, gum chewing, water drinking, and vitamin and mineral supplementation. School lunch menus were also obtained to help subjects with recall. The usual time for an interview was $25-40$ minutes.

Interview schedules were programed so that each participant was interviewed for different days of the week, including weekend days, and at different seasons of the year. Interviews were carried out in rooms assigned to the study at schools, and at home during weekends and summer holidays. During the course of the study, a parent or guardian of each participant completed a questionnaire on family income and educational attainment, fluoride history, dental attendance, and related subjects.

Analysis was carried out for those 499 children, initially aged 11-15, who completed at least three dietary interviews and were present for baseline and final dental examinations. All data for total sugars consumption and for frequency of ingestion were taken from the 24-hour recalls rather than from the food frequency questionnaire. While total sugars could have been quantified as the average, from all interviews, of grams of sugars consumed per day, this variable would have required results to be age-adjusted because of greater food consumption by the older children. It was found, however, that ingestion of sugars quantified as the average proportion of daily energy intake across all interviews was well-correlated with absolute consumption $(r=0.56)$ and had the advantage of not varying with age. This variable, referred to as "sugars\%", could therefore be used in analyses without the need to age-adjust results, thus simplifying their presentation. The same approach was taken with consumption of sugars between meals: Here the variable was referred to as "between-meal sugars\%". Average number of eating occasions was the mean of all meals and snacks reported by each child in all interviews. A high-sugar food was one containing $15 \%$ or more of all sugars by weight. Any between-meal ingestion of at least one such food was considered a high-sugar snack.

\section{Results.}

Dietary status. - The average daily energy intake for the 259 males was $10.14 \mathrm{MJ}$ (standard deviation \pm 2.40 ), and for the 240 females it was $7.95 \mathrm{MJ}( \pm 1.65)$. These are averages of each child's mean intake from all interviews over three years. Males averaged $156 \mathrm{~g}( \pm 46.8)$ of sugars per day and females $127 \mathrm{~g}( \pm 34.7)$ per day $(58 \mathrm{~kg}$ and $46 \mathrm{~kg}$ per year, respectively). In both sexes, sugars provided more than one-quarter of total energy intake

Dental caries. - The DMFS prevalence of the 499 participants at baseline is shown in Table 1, and DMFS increment is shown in Table 2 . Almost $30 \%$ of the group had zero caries increment; $81 \%$ of new lesions were pit-and-fissure lesions (buccal pits and lingual extensions as well as occlusal lesions). No buccal and lingual smooth-surface lesions were found. The group as a whole averaged less than one new DMF surface per year. Girls averaged 3.1 ( \pm 3.7$)$ DMFS surfaces and boys $2.7( \pm 3.6)$ over the three years.

Caries increment and: (a) Average daily consumption of sugars. - Relations between caries increment and sugars \% were examined several ways. The first compared high-sugars and low-sugars consumers in terms of caries increment. Low-sugars consumers were defined as those below the 25 th percentile of sugars $\%$ (for whom $23.5 \%$ or less of energy intake came from sugars) and high-sugars consumers as those above the 
TABLE 1

BASELINE CARIES EXPERIENCE OF ALL PARTICIPANTS IN THE MICHIGAN DIET/DENTAL CARIES STUDY, 1982-1985

\begin{tabular}{crccc}
\hline $\begin{array}{c}\text { Age at } \\
\text { Baseline }\end{array}$ & $\mathrm{n}$ & $\begin{array}{c}\text { Percent } \\
\text { Caries-free }\end{array}$ & $\begin{array}{c}\text { Mean } \\
\text { DMFS } \\
\text { (SD) }\end{array}$ & $\begin{array}{c}\text { Percent* } \\
\text { Pit-and-Fissure } \\
\text { Lesions }\end{array}$ \\
\hline 10 & 15 & 40.0 & $1.7(2.2)$ & 96.2 \\
11 & 142 & 23.2 & $3.7(3.5)$ & 92.8 \\
12 & 153 & 18.3 & $4.0(3.6)$ & 90.5 \\
13 & 116 & 25.0 & $4.7(4.8)$ & 92.0 \\
14 & 61 & 21.3 & $5.9(6.1)$ & 87.7 \\
15 & 12 & 16.7 & $5.2(4.4)$ & 92.1 \\
\hline All & 499 & 22.2 & $4.3(4.3)$ & 91.1 \\
\hline
\end{tabular}

*Includes occlusal surfaces and buccal surfaces of mandibular molars and lingual surfaces of maxillary molars.

TABLE 2

CARIES INCREMENTS OF ALL PARTICIPANTS OVER THREE YEARS (MICHIGAN DIET/DENTAL CARIES STUDY, 1982-1985)

\begin{tabular}{|c|c|c|c|c|}
\hline $\begin{array}{c}\text { Age at } \\
\text { Baseline }\end{array}$ & $n$ & $\begin{array}{c}\text { Percent } \\
\text { Zero } \\
\text { Increment }\end{array}$ & $\begin{array}{c}\text { Mean } \\
\text { DMFS } \\
\text { Increment } \\
\text { (SD) }\end{array}$ & $\begin{array}{c}\text { Percent* } \\
\text { Pit-and-Fissure } \\
\text { Increment } \\
\end{array}$ \\
\hline 10 & 15 & 46.7 & $2.1(3.5)$ & 96.8 \\
\hline 11 & 142 & 31.0 & $2.6(3.1)$ & 84.0 \\
\hline 12 & 153 & 26.1 & $3.3(4.0)$ & 83.2 \\
\hline 13 & 116 & 29.3 & $2.7(2.8)$ & 83.1 \\
\hline 14 & 61 & 27.9 & $3.5\{4.8\}$ & 72.5 \\
\hline 15 & 12 & 58.3 & $1.9(4.6)$ & 30.4 \\
\hline All & 499 & 29.9 & $2.9(3.6)$ & 81.3 \\
\hline
\end{tabular}

*Includes occlusal surfaces and buccal surfaces of mandibular molars and lingual surfaces of maxillary molars.

TABLE 3

CARIES EXPERIENCE OF CHILDREN IN THE MICHIGAN DIET/ DENTAL CARIES STUDY, 1982-85, BY TOTAL INTAKE OF SUGARS

\begin{tabular}{lccc}
\hline \hline & \multicolumn{3}{c}{$\begin{array}{c}\text { Sugars Intake as Percent of To- } \\
\text { tal Calories }\end{array}$} \\
\cline { 2 - 4 } & $\begin{array}{r}525 \text { th } \\
\text { percentile } \\
(\mathrm{n}=124)\end{array}$ & $\begin{array}{c}\geq 75 \text { th } \\
(\mathrm{n}=125)\end{array}$ & $\mathrm{p}^{*}$ \\
\hline Mean baseline age in years & 12.04 & 12.27 & 0.11 \\
Mean DMFS increment & 2.40 & 3.05 & 0.15 \\
Baseline DMFS & 3.46 & 5.34 & 0.00 \\
Final DMFS & 5.86 & 8.39 & 0.00 \\
DMFS increment:approximal surfaces & 0.19 & 0.65 & $0.06^{+}$ \\
DMFS increment:pits and fissures & 2.11 & 2.36 & $0.48^{+}$ \\
\hline * $t$ test. & \multicolumn{3}{c}{} \\
'p-value after adjustment for baseline age and baseline DMFS. \\
\hline
\end{tabular}

75th percentile (for whom $29.5 \%$ or more of energy intake came from sugars). The average daily intake of sugars for children at or below the 25 th percentile was $109 \mathrm{~g}$; at or above the 75 th percentile, it was $175 \mathrm{~g}$. Comparison of five caries variables for the low-sugars and high-sugars consumers is shown in Table 3. The principal finding was the small and non-significant difference in the increment of pit-and-fissure lesions, but the three-fold difference in the increment of approximal caries bordered on statistical significance $(p=0.06)$.

The second analysis was to compare children with high and low caries increments for a selection of dietary variables (Table 4). Definitions of high and low caries increments were taken from the frequency distribution. Those with zero increment ( $\mathrm{n}$ $=149$ ) constituted the low-caries group, while those who developed two or more approximal lesions during the study (n
$=51$ ) were the high-caries group. Socioeconomic differences can be seen between the groups in Table 4, as can several significant differences in dietary patterns.

(b) Average daily number of eating occasions. - Children in the study reported an average of 4.3 eating occasions per day, meals and snacks combined, ranging from 2.0 to 6.8 . Average daily eating occasions were not related to age. The 25 th and 75 th percentiles of average daily eating occasions -4.0 and 4.8 occasions, respectively-were compared for baseline age and a set of caries variables shown in Table 5, from which little pattern emerges.

Because the variability in average daily eating occasions was not high, the relationship between caries and the extremes of average daily eating occasions was examined (Table 6). There were 14 children who averaged fewer than 3.25 eating occasions per day and 47 who averaged 5.25 or more, but the results in Table 6 still show little difference between groups.

(c) Average daily number of high-sugar snacks. - As found with total eating occasions, intake of sugary foods between meals was not age-dependent. The question was addressed by comparing those children who averaged 0.5 or fewer sugary between-meal snacks per day $(\mathrm{n}=179)$ with those who averaged 1.0 or more sugary between-meals snacks per day (n $=176$ ).

Table 7 presents the same five caries variables given in Tables 5 and 6 according to low or high average daily number of sugary snacks between meals. While there is a tendency toward greater caries increment in the higher-intake group, it does not achieve statistical significance when adjusted for age and baseline DMFS. The difference between groups in the increment of approximal caries was no greater than that seen with pit-and-fissure surfaces.

(d) Average daily consumption of sugars between meals. From the distribution of consumption of sugars between meals as a proportion of daily energy intake (between-meal sugars\%), those below the 25 th percentile were classified as low consumers of between-meal sugars\%, those above the 75 th percentile as high consumers.

For the whole group of 499 children, between-meal consumption of sugars averaged $7.5 \%$ of daily caloric intake. For those below the 25 th percentile $(n=125)$, between-meal sugars averaged $4.8 \%$ of daily caloric intake $(17.2 \mathrm{~g})$; for those above the 75 th percentile, it was $9.9 \%(66.4 \mathrm{~g})$. Table 8 shows the same series of caries variables as before for the 25 th and 75 th percentiles of between-meal sugars $\%$ consumption. In contrast to earlier results, some significant differences emerge in Table 8 . While overall caries increment differed by a nonsignificant $0.78 \mathrm{DMF}$ surfaces $(\mathrm{p}=0.09$ ), there were significant differences in baseline and final DMFS values, and a three-fold difference in extent of approximal caries $(p=0.05$, adjusted for age and baseline DMFS). By comparison, there was only a non-significant difference of $13.4 \%$ in pit-andfissure caries ( $p=0.50$ ). However, the small absolute dimension of the large relative difference in approximal caries increment should be noted.

Snacking patterns of children with high and low caries increments are included in Table 4 . While distinctions are not clear-cut, the high-caries group is seen to eat fewer meals and more snacks, and to receive more of their energy intake from snack carbohydrates and snack sugars. They also ingest a higher proportion of energy intake from sugars, snack carbohydrates, and snack sugars, and a low proportion from meal protein.

Linear and logistic regression analyses were carried out in order to test the effects of potential confounders on the sugarscaries relationships. The self-reported variables of (a) previous residence in a fluoridated community, (b) use of fluoride tablets, (c) frequency of topical fluoride applications, (d) tooth- 
TABLE 4

COMPARISONS BETWEEN LOW-CARIES CHILDREN AND THOSE WITH HIGH APPROXIMAL-SURFACE CARIES FOR SELECTED VARIABLES

\begin{tabular}{|c|c|c|c|}
\hline \multirow[b]{2}{*}{ Variable } & \multicolumn{2}{|c|}{ Caries } & \multirow[b]{2}{*}{$\mathrm{p}^{+}$} \\
\hline & $\begin{array}{c}\text { Lowt } \\
\mathbf{n}=149 \\
\end{array}$ & $\begin{array}{c}\text { High } \ddagger \\
\mathrm{n}=51\end{array}$ & \\
\hline Age in years at end of study & 15.2 & 15.3 & 0.53 \\
\hline Percent with a family income more than $\$ 25,000$ & 49.6 & 24.4 & $<0.01$ \\
\hline Percent with parents who attended college & 56.1 & 35.4 & 0.01 \\
\hline Percent reporting taking $\mathrm{F}$ tablets & 36.2 & 31.9 & 0.37 \\
\hline Percent reporting frequent topical $\mathrm{F}$ & 32.5 & 26.1 & 0.27 \\
\hline Percent reporting brushing $2 /$ day or more & 53.8 & 47.9 & 0.30 \\
\hline Joules total per day & 8.98 & 9.01 & 0.94 \\
\hline \multicolumn{4}{|l|}{ Joules from: } \\
\hline total sugars & 2.31 & 2.41 & 0.41 \\
\hline meals & 7.59 & 7.35 & 0.42 \\
\hline meal sugars & 1.66 & 1.63 & 0.66 \\
\hline snacks & 1.39 & 1.67 & 0.06 \\
\hline snack protein & 0.11 & 0.12 & 0.46 \\
\hline snack fat & 0.44 & 0.51 & 0.17 \\
\hline snack carbohydrate & 0.87 & 1.06 & 0.03 \\
\hline snack sugars & 0.64 & 0.78 & 0.04 \\
\hline meals with at least one high-sugars food ( $\geq 15 \%)$ & 1.16 & 1.11 & 0.63 \\
\hline snacks with at least one high-sugars food & 0.59 & 0.71 & 0.16 \\
\hline all eating occasions with at least one high-sugars food & 1.75 & 1.82 & 0.66 \\
\hline eating after $9 \mathrm{pm}$ & 0.12 & 0.16 & 0.34 \\
\hline \multicolumn{4}{|l|}{ Percent of total Joules from: } \\
\hline meals & 84.6 & 82.2 & 0.07 \\
\hline meal sugars & 18.5 & 18.4 & 0.92 \\
\hline snacks & 15.3 & 17.7 & 0.07 \\
\hline snack sugars & 7.1 & 8.4 & 0.04 \\
\hline
\end{tabular}

$\uparrow \mathrm{DMFS}=0$ increment over three years.

$\$ 2$ or more approximal-surface lesions over three years.

${ }^{+} t$ test, except for variables $2-5$, which are Fisher's exact probability.

TABLE 5

CARIES EXPERIENCE OF CHILDREN IN THE MICHIGAN DIET/ DENTAL CARIES STUDY, 1982-85, BY AVERAGE NUMBER OF EATING OCCASIONS (i.e., MEALS AND SNACKS) PER DAY

\begin{tabular}{lccc}
\hline \hline & $\begin{array}{c}\text { Mean Eating Occa- } \\
\text { sions per Day }\end{array}$ \\
\cline { 2 - 3 } & $\begin{array}{c}\leq 25 \text { th } \\
\text { percentile }\end{array}$ & $\begin{array}{c}\geq 75 \text { th } \\
\text { percentile }\end{array}$ & \\
& $\mathrm{n}=197$ & $\mathrm{n}=131$ & $\mathrm{p}^{*}$ \\
\hline Mean baseline age in years & 12.08 & 12.42 & 0.01 \\
Mean DMFS increment & 2.93 & 3.15 & 0.59 \\
Baseline DMFS & 4.15 & 5.07 & 0.08 \\
Final DMFS & 7.08 & 8.22 & 0.12 \\
DMFS increment:approximal surfaces & 0.43 & 0.69 & $0.399^{+}$ \\
DMFS increment:pits and fissures & 2.43 & 2.28 & $0.60^{+}$ \\
\hline${ }^{*} t$ test. & \multicolumn{3}{c}{} \\
${ }^{*} \mathrm{p}$-value after adjustment for baseline age and baseline DMFS. \\
\hline
\end{tabular}

brushing frequency, (e) antibiotic use, (f) educational level of parents, (g) family income, (h) sex, and (i) baseline age did not disturb the relationships previously described (data not tabulated). It is emphasized that the regression analyses tested the effects of these potential confounders on the sugars-caries relationships, not their independent effects on caries increment.

\section{Discussion.}

It was noted by Rugg-Gunn et al.(1984) that since longitudinal studies of diet and caries are rare, methodological issues merit particular discussion prior to an assessment of the results.

(a) Methods. - We chose to use 24 -hour dietary recalls be-
TABLE 6

CARIES EXPERIENCE OF CHILDREN IN THE MICHIGAN DIET/ DENTAL CARIES STUDY, 1982-85, BY AVERAGE NUMBER OF EATING OCCASIONS (i.e., MEALS AND SNACKS) PER DAY

\begin{tabular}{lccc}
\hline & \multicolumn{3}{c}{$\begin{array}{c}\text { Mean Eating Occa- } \\
\text { sions per Day }\end{array}$} \\
\cline { 2 - 3 } & $<3.25$ & $\geq 5.25$ & \\
& $\mathrm{n}=14$ & $\mathrm{n}=47$ & $\mathrm{p}^{*}$ \\
\hline Mean baseline age in years & 12.4 & 12.6 & 0.43 \\
Mean DMFS increment & 3.6 & 3.3 & 0.80 \\
Baseline DMFS & 4.4 & 5.3 & 0.62 \\
Final DMFS & 8.1 & 8.6 & 0.82 \\
DMFS increment:approximal surfaces & 0.8 & 0.8 & $0.57^{+}$ \\
DMFS increment:pits and fissures & 2.6 & 2.4 & $0.99^{+}$ \\
\hline
\end{tabular}

${ }^{*} t$ test.

${ }^{+}$p-value after adjustment for baseline age and baseline DMFS.

cause there is no standard method for documenting dietary intake, and because 24-hour recalls seemed most practical for this study. While deficiencies in the 24-hour recall method have been described (Hegsted, 1972; Garn et al., 1976; Gersovitz et al., 1978; Greger and Entyre, 1978), other studies show that children can provide valid estimates of the food they consumed the previous day (Emmons and Hayes, 1973; Burk and Pao, 1976; Frank et al., 1977). Other approaches used in recent studies of diet and caries include a three-day diary followed by interview (Rugg-Gunn et al., 1984) and seven-day diaries, the validity of both of which has been questioned (Stecksen-Blicks et al., 1985) and defended (Holund et al., 1985). Consistency of data was enhanced by use of the interview protocol and food models.

While there is little guidance in the nutritional literature on 
TABLE 7

CARIES EXPERIENCE IN CHILDREN IN THE MICHIGAN DIET/ DENTAL CARIES STUDY, 1982-85, WITH HIGH AND LOW INTAKES OF HIGH-SUGARS FOODS BETWEEN MEALS

\begin{tabular}{lccc}
\hline \hline & $\begin{array}{c}\text { Low } \\
\text { Intakes } \uparrow \\
\mathrm{n}=179\end{array}$ & $\begin{array}{c}\text { High } \\
\text { Intakes } \\
\mathrm{n}=176\end{array}$ & $\mathrm{p}^{*}$ \\
\hline Mean baseline age in years & 12.1 & 12.3 & 0.10 \\
Mean DMFS increment & 2.6 & 3.0 & 0.35 \\
Baseline DMFS & 3.9 & 4.7 & 0.08 \\
Final DMFS & 6.5 & 7.7 & 0.08 \\
DMFS increment:approximal surfaces & 0.4 & 0.6 & $0.51^{+}$ \\
DMFS increment:pits and fissures & 2.1 & 2.3 & $0.56^{+}$ \\
\hline
\end{tabular}

t0.5 or fewer average intakes per day, between meals, of food containing $15 \%$ or more of sugars by weight.

$\$ 1.0$ or more average intakes per day, between meals, of food containing $15 \%$ or more of sugars by weight.

${ }^{*} t$ test.

+p-value after adjustment for baseline age and baseline DMFS.

TABLE 8

CARIES EXPERIENCE OF CHILDREN IN THE MICHIGAN DIET/ DENTAL CARIES STUDY, 1982-85, BY AVERAGE INTAKE OF SUGARS BETWEEN MEALS

\begin{tabular}{|c|c|c|c|}
\hline & \multicolumn{3}{|c|}{$\begin{array}{l}\text { Snack Sugars as a Percent of To- } \\
\text { tal Calories }\end{array}$} \\
\hline & $\begin{array}{c}\leq 25 \text { th } \\
\text { percentile } \\
\mathrm{n}=125\end{array}$ & $\begin{array}{c}\geq 75 \text { th } \\
\text { percentile } \\
\mathrm{n}=125\end{array}$ & $\mathrm{p}^{*}$ \\
\hline Mean baseline age in years & 12.08 & 12.26 & 0.22 \\
\hline Mean DMFS increment & 2.42 & 3.20 & 0.09 \\
\hline Baseline DMFS & 3.49 & 4.67 & 0.03 \\
\hline Final DMFS & 5.92 & 7.87 & 0.01 \\
\hline DMFS increment:approximal surfaces & 0.22 & 0.69 & $0.05^{+}$ \\
\hline DMFS increment:pits and fissures & 2.13 & 2.46 & $0.50^{+}$ \\
\hline
\end{tabular}

the optimum number of interviews needed to capture dietary patterns accurately, choice of the multiple-interview approach for this study was influenced by the work of Beaton et al. $(1979,1983)$, who demonstrated that a set of dietary interviews results in less variance than a single interview. Just under $70 \%$ of the 499 children in this study granted four interviews.

We found that the definition of "between-meal" consumption was complicated by the variability of eating patterns. In addition to noting time of day at which food was consumed, participants were asked what they considered each consumption to be. For analysis, definition of meals could then be made either by time of day (e.g., food consumed between $6 \mathrm{a} . \mathrm{m}$. and 9 a.m. was breakfast) or as defined by the participant. For example, if the child slept late and had her first food intake of the day at 11 a.m., should that be called breakfast, brunch, lunch, or a snack? If the same child had risen at 7 a.m. and worked several hours before the first food intake at 10 a.m., should the decision be the same? On consideration, we decided to use the child's own definition of the food intake.

In this study, we averaged intake frequency from a series of standardized interviews. A single dietary interview per participant is likely to result in a more variable distribution,while averaging from several interviews has the effect of reducing extremes of variability. The impact of an atypical day is weakened when added to several days of normal consumption. Multiple dietary recordings, as employed in this study and in that of Rugg-Gunn et al. (1984), probably reflect real-life food consumption over a period of time more accurately than does a single dietary interview.
The number of eating occasions per day, 4.3 on average, does not look high to those who assume that teenagers spend all their time snacking. Our definition of an eating occasion, up to 20 minutes between ingestion of food items, was based on the Stephan curve (Stephan, 1940, 1944). That 20-minute definition, however, might have served to compress the number of intakes recorded. For example, if a child ate a hamburger after school, a bag of fries 15 minutes after that, and finished off with a soft drink 15 minutes later, these ingestions would all be recorded as one eating occasion. By contrast, Rugg-Gunn et al. (1984) used 15 minutes between ingestions as their definition of an eating occasion, meaning that in the example just given they would have counted three intakes rather than one. Rugg-Gunn et al. (1984) recorded a mean of 6.8 eating occasions per day, higher than our study's mean of 4.3 . The difference could have resulted from the 15 versus $20 \mathrm{~min}$ utes definition of an eating occasion, or it could reflect different eating patterns in English children compared with those in Michigan.

The definition of $15 \%$ content of sugars by weight as the dividing line between "high-sugar" and "low-sugar" foods was chosen because that level was just above the 80th percentile of sugars content of all foods reported, which seemed appropriate. Further support for the $15 \%$ cut comes from Newbrun (1982), who stated that foods containing 15-20\% sugars must be considered "unsafe" as snack foods, and that those with 10-15\% sugars are contra-indicated for eating between meals. Animal studies also support the 15\% cut; Huxley (1977) found that increasing the sucrose content of foods above $15 \%$ did not increase their cariogenicity in most rat models studied.

(b) Results. - We had originally hoped to compare the relative cariogenicity of various sugars, given the high proportion of monosaccharides in the modern American diet (Burt, 1985). This subject has been studied previously (Koulourides et al. 1976; Colman et al., 1977; Okuda and Frostell, 1981; Frostell et al., 1981), though conclusions for human populations are not clear-cut. We could not address this issue adequately, however, because a number of foods in the data bank did not have different sugar constituents recorded, and many had only "total sugars" listed. Even if full sugars data were available, some foods changed their sugar constituents during the course of the project in response to price of ingredients or perceived marketing improvement. The leading soft drink manufacturers, for example, switched their principal sweetener from sucrose to high-fructose corn syrup in November, 1983 (U.S. Department of Agriculture, 1984). Relative cariogenicity of different sugars is a difficult subject to study in representative human populations.

Conclusions on the specific cariogenic role of sugary foods ( $15 \%$ or more of sugars) could not be reached from this study. Table 4 shows that the high-caries group did not eat highsugars foods more often, nor did they have a greater energy intake from high-sugars foods. One recognized problem in studying the cariogenicity of sugary foods is "background noise", meaning the difficulty of trying to assess the impact of one particular food against a background of generally highsugars intake (Stecksen-Blicks et al., 1985; Sundin et al., 1983; Bergendal and Hamp, 1985). In modern child populations, a study design would have to be of extraordinary sensitivity to detect the same effects of high-sugars foods which can be demonstrated in animal studies.

Table 7 shows that no differences in caries increment could be detected between those with high and low frequency of intake of sugary foods between meals, in contrast to the effects of the average amounts of sugars consumed between meals, shown in Table 8. These two analyses compare different children, but they demonstrate that the frequency-of-consumption 
issue is not clear-cut. The finding that one-quarter of total energy came from all sugars whereas only $7.5 \%$ came from between-meal sugars at first appears surprising, but it stems from our quantification of all sugars, not just sucrose. Milk, fruit juice, and soft drinks provide a lot of sugars to total intake (but not to sucrose intake). When consumed with meals, they contribute to total sugars but not to snack sugars, thus reducing the proportion of sugars attributable to snacks in the total diet. Different methods of recording meals and snacks, such as used by Frank et al. (1977), might provide different proportions.

There was a significant relationship between caries increment and total consumption of sugars between meals, which suggests some impact from snacking. But even there, betweenmeal consumption of sugars seemed to have no greater effect on caries development than did total sugars. This could be because between-meal sugars contributed a relatively small proportion of total energy intake, or it could be related to the subjective method of determining meals and snacks.

Results of this study are generally similar to those in the two-year longitudinal study of Rugg-Gunn et al. (1984), despite probable differences in eating habits between English and American children and the previously-described methodological differences. As in our study, Rugg-Gunn et al. found generally weak relationships between caries increments and dietary variables, and relationships were stronger with total sugars intake than with frequency. The Michigan children appeared to consume more sugars, $142 \mathrm{~g}$ per day as against 118 $\mathrm{g}$ for the English children, and sugars provided $26.5 \%$ of total energy intake (sugars\%) for the Michigan group as against $21 \%$ for the English children. The Michigan children were a little older: 12.2 years on average at baseline compared with 11.5.

In their review, Burt and Ismail (1986) suggested that the frequency/caries relationship might be stronger where sugars consumption is generally lower; it might also have been stronger in previous years when caries incidence was higher, especially on approximal surfaces. It is likely that in the well-fed, convenience-food-oriented population in which our study was conducted, there was simply not enough variability in the frequency of eating to discriminate between extremes, and caries incidence was relatively low and predominantly in pits and fissures. As a result, the weak relationship between frequency and caries in our study and in that of Rugg-Gunn et al. (1984) should not be surprising.

Reflecting further on the lack of a clear caries/frequency-ofeating relationship, it is likely that a distorted view of the caries-frequency hypothesis came from Vipeholm (Gustafsson et al., 1954). This landmark study reported extremes of consumption of a type rarely found in the mainstream of everyday life. Certainly there was no eating behavior in our study, nor apparently in that of Rugg-Gunn et al. (1984), which even came close to one Vipeholm group's daily consumption of 24 large sticky toffees. As a result, we suggest that the conclusions of the Vipeholm study, at least with respect to the etiological importance of eating frequency, might not be relevant to the average teenager. Our results, however, demonstrate that between-meal consumption of sugars is still a risk factor for the most caries-susceptible children.

Study results are dominated by the low caries increment and high consumption of sugars. The low caries increment is typical of that found in many parts of the United States and can be attributed to a number of factors, notably fluoride exposure. The most important aspect of the high consumption of sugars is the absence of variability; only four children averaged less than $50 \mathrm{~g}$ of sugars per day. Such consumption levels seem to be above suggested thresholds for humans, although it is not certain how total sugars intake relates to thresholds developed from studies with sucrose. Animal studies support the thresh- old concept (Huxley, 1977; Hefti and Schmid, 1979), and in humans the epidemiological evidence suggests a sucrose threshold of about $15 \mathrm{~kg}$ per year, or $40 \mathrm{~g}$ per day (Sreebny, 1982b; Sheiham, 1983). Our definitions of low and high consumers of total sugars therefore have to be seen as strictly relative; by global standards all were high. A true test of the threshold hypotheses would have to be carried out in populations with greater variability in sugars consumption, and where distinctions could be reliably drawn between consumption of sucrose and other sugars.

As part of the caries decline, the proportion of smoothsurface lesions, both approximal and buccal-lingual, is also declining (Bohannan et al., 1984). This trend was apparent in our study, and the dominance of pit-and-fissure lesions, some $81 \%$ of incident lesions, clearly influenced our results. Plaque adhesion is critical in smooth-surface caries (Firestone and Mühlemann, 1985), less so in pit-and-fissure caries (McDonald and Stookey, 1977). Sugars, especially sucrose, may enhance the ability of Streptococcus mutans to adhere to tooth surfaces (Bowen, 1978), so the stronger associations found between approximal caries increment and consumption of sugars are to be expected. But because there was little approximal caries during this study, the impact of this finding on total caries experience was relatively minor.

If the group studied is representative, results suggest that the etiological role of sugars in caries may have weakened under modern conditions in the United States. In child populations where caries is dominated by pit-and-fissure lesions, the importance of sugars in caries incidence may not be as pronounced as it was when approximal and smooth-surface caries was more common. Total intake of sugars and intake of sugars between meals still appear to be risk factors in children who are susceptible to approximal caries.

\section{Acknowledgments.}

The authors would like to acknowledge the dedication shown by the dietitian/interviewers, Helen Gallagher and Vicki Kearney, interviewer Anna Mobley, and field coordinators Lynda Chan and Carol Coyle, during this study. The first-rate cooperation of the superintendents, principals, teachers, and students in the school systems of Coldwater, Quincy, and Union City is also gratefully acknowledged.

\section{REFERENCES}

AMERICAN DENTAL ASSOCIATION (1968): Council on Dental Research and Council on Dental Therapeutics. Proceedings of the Conference on the Clinical Testing of Cariostatic Agents, Chicago: American Dental Association, Oct. 14-16.

BAGRAMIAN, R.A. and RUSSELL, A.L. (1973): Epidemiologic Study of Dental Caries Experience and Between-Meal Eating Patterns, $J$ Dent Res 52:342-347.

BAGRAMIAN, R.A.; JENNY, J.; FRAZIER, P.J.; and PROSHEK, J.M. (1974): Diet Patterns and Dental Caries in Third Grade U.S. Children, Community Dent Oral Epidemiol 2:208-213.

BAUME, L.J. (1969): Caries Prevalence and Caries Intensity Among 12,444 Schoolchildren of French Polynesia, Arch Oral Biol 14:181205.

BEATON, G.H.; MILNER, J.; COREY, P.; McGUIRE, V.; COUSINS, M.; STEWART, E.; de RAMOS, M.; HEWITT, D.; GRAMBSCH, P.V.; KASSIM, N.; and LITTLE, J.A. (1979): Sources of Variance in 24-Hour Dietary Recall Data: Implications for Nutrition Study Design and Interpretation, Am $J$ Clin Nutr 32:2546-2559.

BEATON, G.H.; MILNER, J.; McGUIRE, V.; FEATHER, T.E.; and LITTLE, J.A. (1983): Source of Variance in 24-Hour Dietary Recall Data: Implications for Nutrition Study Design and Inter- 
pretation, Carbohydrate Sources, Vitamins, and Minerals, $A m J$ Clin Nutr 37:986-995.

BERGENDAL, B. and HAMP, S.E. (1985): Dietary Pattern and Dental Caries in 19-Year-Old Adolescents Subjected to Preventive Measures Focused on Oral Hygiene and/or Fluorides, Swed Dent J 9:1-7.

BIBBY, B.G. (1978): Dental Caries, Caries Res 12 (Suppl 1):3-6.

BOHANNAN, H.M.; DISNEY, J.A.; GRAVES, R.C.; BADER, J.D.; KLEIN, S.P.; and BELL, R.M. (1984): Indications for Sealant Use in a Community-Based Preventive Dentistry Program, $J$ Dent Ed 48(Suppl):45-55.

BOWEN, W.H. (1978): Role of Carbohydrates in Dental Caries. In: Sweeteners and Dental Caries, J.H. Shaw and G.G. Roussos, Eds., Washington, DC: Information Retrieval, pp. 147-152.

BOWEN, W.H.; AMSBAUGH, S.M.; MONELL-TORRENS, S.; and BRUNELLE, J. (1983): Effect of Varying Intervals between Meals on Dental Caries in Rats, Caries Res 17:466-471.

BOWEN, W.H. and BIRKHED, D. (1986): Dental Caries: Dietary and Microbiology Factors. In: Systematized Prevention of Oral Disease; Theory and Practice, L. Granath and W.D. McHugh, Eds., Boca Raton: CRC, pp. 19-41.

BUNTING, R.W. (1935): Diet and Dental Caries, $J$ Am Dent Assoc 22:114-122.

BURK, M. and PAO, E. (1976): Methodology for Large-Scale Surveys of Household and Individual Diets, US Dept of Agriculture, Agriculture Research Service, Home Economics Research Rep No. 40. Washington, DC: Government Printing Office.

BURT, B.A. (1985): The Future of the Caries Decline, $J$ Publ Health Dent 45:261-269.

BURT, B.A. and ISMAIL, A.I. (1986): Diet, Nutrition, and Food Cariogenicity, $J$ Dent Res 65 (Spec Iss):1475-1484.

CLANCY, K.L.; BIBBY, B.G..; GOLDBERG, H.J.V.; RIPA, L.W.; and BERNICE, J. (1977): Snack Food Intake of Adolescents and Caries Development, $J$ Dent Res 56:568-573.

COLLINS, R.O.; JENSEN, A.L.; and BECKS, H. (1942): Study of Caries-free Individuals: II. Is an Optimum Diet of a Reduced Carbohydrate Intake Required to Arrest Dental Caries?, $J$ Am Dent Assoc 29:169-178.

COLMAN, G.; BOWEN, W.H.; and COLE, M.F. (1977): The Effects of Sucrose, Fructose, and a Mixture of Glucose and Fructose on the Incidence of Dental Caries in Monkeys ( $M$. fascicularis), Br Dent J 142:217-221.

CURZON, M.E. and CURZON, J.A. (1970): Dental Caries in Eskimo Children of the Keewatin District in the Northwest Territories, $J$ Can Dent Assoc 36:342-345.

DUANY, L.F.; ZINNER, D.D.; and JABLON, J.M. (1972): Epidemiologic Studies of Caries-free and Caries-active Students. II. Diet, Dental Plaque, and Oral Hygiene, $J$ Dent Res 51:727-733.

EMMONS, L. and HAYES, M. (1973): Accuracy of 24-Hour Recalls of Young Children, $J$ Am Dietet Assoc 62:409-415.

FINN, S.B. and GLASS,R.B. (1975): Sugar and Dental Decay, World Rev Nutr Diet 22:304-326.

FIRESTONE, A.R.; SCHMID, R.; and MÜHLEMANN, H.R. (1984): Effect of the Length and Number of Intervals Between Meals on Caries in Rats, Caries Res 18:128-133.

FIRESTONE, A.R. and MÜHLEMANN, H.R. (1985): In vivo $\mathrm{pH}$ of Plaque-covered and Plaque-free Interdental Surfaces in Humans Following a Sucrose Rinse, Clin Prev Dent 7:24-26.

FISHER, F.J. (1968): A Field Survey of Dental Caries, Periodontal Disease and Enamel Defects in Tristan da Cunha, Br Dent $J$ 125:447-453.

FRANK, G.; BERENSON, G.S.; SCHILLING, P.E.; and MOORE, M.C. (1977): Adapting the 24-Hour Recall for Epidemiologic Studies of School Children, J Am Dietet Assoc 71:26-35.

FROSTELL, G.; BLOMQUIST, T.; BRUER, P.; DAHL, G.M.; FJELLSTROM, A.; HENDRIKSON, C.-O.; LARJE, O.; NORD, C.-E.; NORDENVALL, K.-J.; and WIK, O. (1981): Reduction of Caries in Pre-School Children by Sucrose Restriction and Substitution With Invert Sugar; the Gustavsberg Study, Acta Odontol Scand 39:333-347.

GARN, S.M.; LARKIN, F.A.; and COLE, P.E. (1976): The Problem With One-Day Dietary Intakes, Ecol Food Nutr 5:245-247.

GERSOVITZ, M.; MADDEN, J.P.; and SMICIKLAS-WRIGHT, H.
(1978): Validity of the 24-Hour Recall and Seven-Day Record for Group Comparisons, $J$ Am Dietet Assoc 73:48-55.

GREGER, J.L. and ENTYRE, G.M. (1978): Validity of 24-Hour Dietary Recalls by Adolescent Females, Am J Publ Health 68:7072.

GUSTAFSSON, B.E.; QUENSEL, C.E.; LANKE, L.S.; LUNDQVIST, C.; GRAHNEN, H.; BONOW, B.E.; and KRASSE, B. (1954): The Vipeholm Dental Caries Study. The Effect of Different Levels of Carbohydrate Intake on Caries Activity in $436 \mathrm{In}$ dividuals Observed for Five Years, Acta Odontol Scand 11:232364.

HANKIN, J.H.; CHUNG, C.S.; and KAU, M.C.W. (1973): Genetic and Epidemiologic Studies of Oral Characteristics in Hawaii's Schoolchildren: Dietary Patterns and Caries Prevalence, $J$ Dent Res 52:1079-1086.

HARGREAVES, J.A. (1980): Sucrose and Total Sugar Intake and Dental Caries of Ontario Children, paper given at the Kellogg Nutrition Symposium, Toronto, ON, Canada.

HARGREAVES, J.A. (1972): Changes in Diet and Dental Health of Children Living in the Scottish Island of Lewis, Caries Res 6:355376.

HARRIS, R. (1963): Biology of the Children of Hopewood House, Bowral, Australia. 4. Observations on Dental Caries Experience Extending Over Five Years (1957-61), J Dent Res 42: 1387-1399.

HEFTI, A. and SCHMID, R. (1979): Effect on Caries Incidence in Rats of Increasing Dietary Sucrose Lcvels, Caries Res 13:298300 .

HEGSTED, D.M. (1972): Problems in the Use and Interpretation of the Recommended Dietary Allowance, Ecol Food Nutr 1:255265.

HOLUND, U.; THEILADE. E.; and POULSEN, S. (1985): Validity of a Dietary Interviewing Method for Use in Caries Prevention, Community Dent Oral Epidemiol 13:219-221.

HUXLEY, H.G. (1977): The Cariogenicity of Dietary Sucrose at Various Levels in Two Strains of Rat Under Unrestricted and Controlled-Frequency Feeding Conditions, Caries Res 11:237-242.

JAKOBSEN, J. (1979): Recent Reorganization of the Public Dental Health Service in Greenland in Favor of Caries Prevention, Community Dent Oral Epidemiol 7:75-81.

JAY, P. (1938): Lactobacillus acidophilus and Dental Caries, Am J Publ Health 28: 759-761.

JAY, P. (1940): The Role of Sugar in the Etiology of Dental Caries, $J$ Am Dent Assoc 27:393-396.

KOHLER, L. and HOLST, K. (1973): Dental Health of Four-YearOld Children, Acta Paediatr Scand 62:269-278.

KÖNIG, K.G.; SCHMID, P.; and SCHMID, R. (1968): An Apparatus for Frequency-controlled Feeding of Small Rodents and its Use in Dental Caries Experiments, Arch Oral Biol 13:13-26.

KOULOURIDES, T.; BODDEN, S.; KELLER, S.; MANSON-HING, L.; LASTRA, J.; and HOUSCH, T. (1976): Cariogenicity of Nine Sugars Tested With an Intraoral Device in Man, Caries Res 10:427441.

LACHAPPELLE-HARVEY, D. and SEVIGNY, J. (1985): Multiple Regression Analysis of Dental Status and Related Food Behaviour of French Canadian Adolescents, Community Dent Oral Epidemiol 13:226-229.

LARSON, R.H.; RUBIN, M.; and ZIPKIN, I. (1962): Frequency of Eating as a Factor in Experimental Dental Caries, Arch Oral Biol 7:463-468.

LITTLETON, N.W.; KAKEHASHI, S.; and FITZGERALD, R. J. (1970): Study of Differences in the Occurrence of Dental Caries in Caucasian and Negro Children, $J$ Dent Res 49:742-751.

McDONALD, J.L. and STOOKEY, G.K. (1977): Animal Studies Concerning the Cariogenicity of Dry Breakfast Cereals, $J$ Dent Res 56:1001-1006.

MAKINEN, K.K. (1972): The Role of Sucrose and Other Sugars in the Development of Dental Caries: A Revicw, Int Dent $J$ 22:363386.

MANDEL, I.D. (1979): Dental Caries, Am Scientist 67:680-688.

MILLER, W.D. (1883): Agency of Micro-organisms in Dccay of Human Teeth, Dent Cosmos 25:1-12.

MOLLER, I.J.; PINDBORG, J.J.; and ROED-PETERSEN, B. (1972): The Prevalence of Dental Caries, Enamel Opacities, and Enamel Hypoplasia in Ugandans, Arch Oral Biol 17:9-22. 
MORGAN, K.J. and ZABIK, M.E. (1981): Amount and Food Sources of Total Sugar Intake by Children Ages 5 to 12 Years, $J$ Clin Nutr 34:404-413.

NEWBRUN, E. (1982): Sucrose in the Dynamics of the Carious Process, Int Dent $J$ 2:13-23.

NEWBRUN, E. (1983): Cariology, 2nd ed., Baltimore: Williams and Wilkins.

NEWBRUN, E.; HOOVER, C.; METTRAUX, G.; and GRAF, H. (1980): Comparison of Dietary Habits and Dental Health of Subjects With Hereditary Fructose Intolerance and Control Subjects, $J$ Am Dent Assoc 101:619-626.

OKUDA, K. and FROSTELL, G. (1981): Effect of Invert Sugar on Accumulation of Streptococcus mutans E49 on the Teeth of Rats, Caries Res 15:515-518.

PEDERSEN, P.O. (1971): Dental Disease in Europe and Greenland, $J R$ Soc Health 91:23-27.

RICHARDSON, B.D.; CLEATON-JONES, P.E.; McINNES, P.M.; RANTSHO, J.M.; and PIETERS, L. (1978): Total Sucrose Intake and Dental Caries in Black and White South African Children Aged 1-6 Years. Part II: Dental Caries and Sucrose Intake, $J$ Dent Assoc S Afr 33:539-544.

RUGG-GUNN, A.J. and EDGAR, W.M. (1984): Sugar and Denta! Caries: a Review of the Evidence, Community Dent Health 1:8592.

RUGG-GUNN, A.J.; HACKETT, A.F.; APPLETON, D.R.; JENKINS, G.N.; and EASTOE, J.E. (1984): Relationship Between Dietary Habits and Caries Increment Assessed Over Two Years in 405 English School Children, Arch Oral Biol 29:983-992.

SCHAMSCHULA, R.G.; COOPER, M.H.; ADKINS, B.L.; BARMES, D.E.; and AGUS, H.M. (1980): Oral Conditions in Australian Children of Aboriginal and Caucasian Descent, Community Dent Oral Epidemiol 8:365-369.

SHEIHAM, A. (1983): Sugars and Dental Decay, Lancet i:282-284.

SREEBNY, L.M. (1982a): Sugar and Human Dental Caries, World Rev Nutr Diet 40: 19-65.

SREEBNY, L.M. (1982b): Sugar Availability, Sugar Consumption, and Dental Caries, Community Dent Oral Epidemiol 10:1-7.

STECKSEN-BLICKS, C.; ARVIDSSON, S.; and HOLM, A.-K. (1985): Dental Health, Dental Care, and Dietary Habits in Children in Different Parts of Sweden, Acta Odontol Scand 43:59-67.

STEPHAN, R.M. (1940): Changes in Hydrogen-ion Concentration on
Tooth Surfaces and in Carious Lesions, $J$ Am Dent Assoc 7:718723.

STEPHAN, R.M. (1944): Intra-oral Hydrogen-ion Concentrations Associated with Dental Caries Activity, $J$ Dent Res 3:257-266.

SUNDIN, B.; BIRKHED, D.; and GRANATH, L. (1983): Is There not a Strong Relationship Nowadays Between Caries and Consumption of Sweets?, Swed Dent J 7:103-108.

TAKEUCHI, M. (1961): Epidemiological Study on Dental Caries in Japanese Children, Before, During, and After World War II, Int Dent $J$ 11:443-457.

TOVERUD, G. (1956): The Influence of War and Post-War Conditions on the Teeth of Norwegian School Children. 1. Eruption of Permanent Teeth and Status of Deciduous Dentition, Millbank Mem Fund $Q$ 314:354-430.

TOVERUD, G. (1957a): The Influence of War and Post-War Conditions on the Teeth of Norwegian School Children. II. Caries in the Permanent Teeth of Children Aged 7-8 and 12-13 Years, Millbank Mem Fund $Q$ 35:127-196.

TOVERUD, G. (1957b): The Influence of War and Post-War Conditions on the Teeth of Norwegian School Children. III. Discussion of Food Supply and Dental Condition in Norway and Other European Countries, Millbank Mem Fund $Q$ 35:373-459.

U.S. DEPARTMENT OF AGRICULTURE, ECONOMIC RESEARCH SERVICE (1984): Sugar and Sweetener; Outlook and Situation Report SSRV9N4. Washington, DC: U.S. Government Printing Office.

U.S. PUBLIC HEALTH SERVICE, NATIONAL INSTITUTE OF DENTAL RESEARCH ( 1981): The Prevalence of Dental Caries in United States Children 1979-80. NIH Publication 82-2245, Washington, DC: U.S. Government Printing Office.

U.S. PUBLIC HEALTH SERVICE, NATIONAL CENTER FOR HEALTH STATISTICS (1982): Diet and Dental Health; a Study of Relationships, DHHS Publ No (PHS) 82-1675. NCHS Report Series 11, No 225. Washington: Government Printing Office.

WEISS, R.L. and TRITHART, A.H. (1960): Between-meal Eating Habits and Dental Caries Experience in Pre-school Children, $A m$ $J$ Publ Health 50:1097-1104.

ZITA, A.C.; MCDONALD, R.E.; and ANDREWS, A.L. (1959): Dietary Habits and Dental Caries Experience in 200 Children, $J$ Dent Res 38:860-865. 